\title{
Multilevel Production Systems with Dependent Demand with Uncertainty of Lead Times
}

\author{
Haibatolah Sadeghi, Ahmad Makui, and Mehdi Heydari \\ Industrial Engineering Department, Iran University of Science and Technology, P.O. Box. 1684613114, Tehran, Iran \\ Correspondence should be addressed to Haibatolah Sadeghi; sadeghi_haibat@yahoo.com
}

Received 10 February 2016; Revised 22 April 2016; Accepted 3 May 2016

Academic Editor: Gisella Tomasini

Copyright ( 2016 Haibatolah Sadeghi et al. This is an open access article distributed under the Creative Commons Attribution License, which permits unrestricted use, distribution, and reproduction in any medium, provided the original work is properly cited.

This study considers a multilevel assembly system with several components in each sublevel. It is assumed that actual lead time for all components is probabilistic; and periodic order quantity (POQ) policy for ordering is utilized. If at a certain level a job is not received at the expected time, a delay is incurred at the delivery of production at this level and this may result in backorders of the finished product. It is assumed in this case that a fixed percentage of the shortage is backlogged and other sales are lost. In the real situation, some but not all customers will wait for backlogged components during a period of shortage, such as for fashionable commodities or high-tech products with the short product life cycle. The objective of this study is to find the planned lead time and periodicity for the total components in order to minimize the expected fixed ordering, holding, and partial backlogging costs for the finished product. In this study, it is assumed that a percentage of components at each level are scrap. A general mathematical model is suggested and the method developed can be used for optimization planned lead time and periodicity for such an MRP system under lead time uncertainties.

\section{Introduction}

Material requirements planning (MRP) is a computer-based set of planning technique that looks at future requirement for a finished product in terms of a master production schedule and utilizes this, together with the bill of materials, inventory status data, and lead time information, to generate the requirements for all the subassemblies, components, and raw materials that make up a finished product [1].

The first computer programs that attempted to perform MRP calculations were produced in the late 1950s and early 1960s in the United States, at a time when business computing was at its infancy. A lot of previous studies on the MRP system have been carried out on the deterministic framework. Nevertheless, in the natural and industrial context, various parameters affect production processes. Material Requirement Planning (MRP) is a systems approach utilized in production processes for planning. Several forms of uncertainty affect the production process such as machine breakdowns, transport delays, and customer demand variations, and different approaches have been advocated for MRP with uncertainty.

In real life situation, the deterministic assumptions embedded in MRP are often too limited [2]. Lead time is a very vital parameter in production and inventory costs. Many literatures on production planning and inventory control assume that lead time is constant or planned to zero but in fact, lead time is hardly constant. In most cases, fluctuations of the lead time greatly decrease the system's performance. To reduce the effects of random factors, companies utilize safety stock (safety lead time), but these stores are expensive. In contrast, if there is no adequate storage, system will have a corresponding shortage and shortage costs. So, the aim of this study is to minimize total costs that include backorders and holding costs. Murthy and $\mathrm{Ma}$ [3] consider a review on MRP with uncertainty because of quality variations in the production process. They started with a brief overview of deterministic MRP and then went on to discuss MRP with uncertainty and the alternate approaches proposed for planning with uncertainty. Yeung et al. [4] propose a review 
on parameters having an impact on the effectiveness of MRP systems under stochastic environments. Guillaume et al. [5] concluded that taking into account the uncertainty of real data in the planning process is a real challenge for companies nowadays. They suggested that, in this communication, the demand uncertainty should be taken into account, alongside the uncertainty on the lead times, for deciding which quantities of components should be released and when.

The research on the uncertainty lead time bias on MRP approach used lot-for-lot or periodic order quantity for ordering the products. The lot-for-lot method places an order for each period in which there is a net requirement. Hence, no inventory is carried from period to period. This method is utilized when setup costs are low or inventory carrying costs are high. The periodic order quantity (POQ) lot sizing method is based on the economic order quantity (EOQ). The POQ method is an adjustment to the EOQ method for timephased demand [6].

There are several publications on one level with multicomponents assembly system. Researcher utilized different method for finding optimal solution such as minimizing the sum of total costs. Song [7] studied a basic continuoustime single-item inventory model where demands form a compound Poisson process and lead times are stochastic. They focused on the behavior of the optimal base-stock level in response to stochastically larger or more variable lead times and reveal that a stochastically larger lead time needs a higher optimal base-stock level. The effect of lead-time variability on optimal policies depends on the inventory cost structure: A more variable lead time needs a higher optimal base-stock level if and only if the unit penalty (holding) cost rate is high (low). Yano [8] utilized an analytic approach to determine optimal planned lead times in serial production systems, in which the actual procurement and processing times may be stochastic, demand is deterministic, and the lot-for-lot policy is utilized. The distribution of lead times is supposed stationary. The considered cost is the sum of inventory holding and job tardiness costs. The author presents a general solution procedure for two-stage serial systems. Chu et al. [9] considered single period model by utilizing lot-for-lot order policy and the objective was to determine planned lead time, to minimize the sum of holding and tardiness costs. The model gives optimal values of the component planned lead times for such a one-level assembly system with random component procurement times.

Ould-Louly and Dolgui [10] utilized Markovian's model for a dynamic multiperiod planning and one-level assembly system with the aim of finding safety lead time, such as to minimize the sum of holding and backlogging costs. Chauhan et al. [11] consider one-level product assembly scenario where some components cannot be stocked because of high component cost and risk. Component lead times are stochastic and associated distribution function is known in advance. The objective is to determine the ordering time for each component so as to minimize the sum of expected holding and backlogging costs. An approach to solve this problem is proposed and the algorithm is tested on a randomly generated data set.
Louly et al. [12] considered one-level assembly system again and utilized a Branch and Bound method for finding optimal planned lead time with lot-for-lot order policy. The goal was to find the optimal MRP offsetting, so as to minimize the sum of setup cost and average holding costs. Sadeghi et al. [13] considered a multiperiod serial production system when lead times for all components are uncertainties. They assumed that lead times for all stages have same distribution and the goal is to minimize the sum of fixed ordering, holding, and backlogging costs. They suggested a general mathematical model and then find optimal planning lead time, ordering quantity, and periodic time.

There are some publications for modelling and solving two levels and multicomponent assembly system. Li et al. [14] studied a two-echelon supply chain inventory model with controllable lead time and service level constraint in fashion supply chains and assume that the unit cost of compressing lead time follows exponential distribution and investigate the optimal ordering quantity and production quantity in the fashion supply chain by minimizing the joint total cost. Hnaien et al. [15] considered two-level assembly systems and utilized genetic algorithm to find the release dates for the components at level 2. Sakiani et al. [16] demonstrated that some reconsideration for the Hnaien et al. research [17] is unavoidable and proved that the main problem in that study is due to wrong mathematical model. This model was corrected by solving a new model through a new approach based on NSGA-II called Guided NSGA-II. Sadeghi et al. [18] consider two-level production and assembly system and proposed a method for finding a planned lead time and periodic order quantity (POQ).

Sadeghi et al. [19] considered supply planning for multiperiod and multiobjective serial production systems under lead-time uncertainties. The objective of this model is to find the planned lead time and periodicity for the total items so as to minimize the expected fixed ordering, holding, and partial backlogging costs and to maximize the customer service level for the finished product. Sadeghi et al. [20] consider a three-level assembly system with various types of components with multiperiod ordering system. The lead time of all components is uncertain and periodic order quantity (POQ) policy is utilized for the planning of components. They modelled three-level assembly system and used MonteCarlo simulation to solve this model. Table 1 summarizes the existing models for assembly systems. Ben Ammar et al. [21] suggest a mathematical model for multilevel assembly systems under a fixed demand and uncertainty of components lead times. The cost function in this study included fixed unit inventory cost, finished product cost, and a backlogging. A mathematical model was suggested for supply planning of multilevel assembly system by using lot-for-lot order policy, but they did not suggest a solution method for this model. Then in a similar research, Ammar et al. [22] utilized genetic algorithm (GA) method to minimize the sum of the average total costs. This reserch does not consider partial backlogging costs and does not consider scrapping for components at each level and order policy is not POQ.

Moreover, in reality, for fashionable commodities and high-tech products with short life cycles, the backorder rate 
is diminishing with the length of waiting time. Customers who experience stock-out will be less likely to buy again from the suppliers; they may turn to another store to purchase the goods. The sales for the product may decline due to the introduction of more competitive product or the change in consumers' preferences. The longer the waiting time, the lower the backlogging rate. This leads to a larger fraction of lost sales and a less profit. As a result, taking the factor of partial backlogging into account is necessary [23].

At the current research multilevel assembly system with partial backlogging, components scrap, and POQ policy is considered. In Table 1, it is obvious that the research for multilevel assembly system is also limited.

In this study, a multilevel assembly system with various types of components in each level is considered. The system costs are sum of fixed ordering cost and holding and partial backordering costs. It is assumed that, in each level, a percentage of components at each level are scrap. A general model is utilized for multilevel MRP under uncertainty components lead times that apparently have not been previously studied. This model utilized MRP approach with periodic order quantity (POQ) policy utilized for the supply planning of components. Table 1 summarizes the existing models for assembly systems under uncertainty lead time.

\section{Notation and Assumptions}

In this study, multiperiod and multilevel production systems under lead-time uncertainties, periodic order quantity (POQ) policy, and partial backordering were considered. The product should be sent at delivery time for customer. If these products were produced before delivery time, they should be held until being delivered to customers and if products were produced after delivery time, then backordering is accrued.

Lead time for each component is uncertain; so, there are three states for each component:

(a) Planned lead time and actual lead time are the same (Figure 1).

(b) Planned lead time is greater than actual lead time (Figure 2).

(c) Planned lead time is smaller than actual lead time (Figure 3).

If actual lead time is equal to planned lead time, there will be no extra cost for the system and if production of a component is finished before planned time, holding cost for this component is added to the system cost.

In each production cycle, the production for needs of $P$ periods should be produced, because the ordering system is POQ. Table 2 shows a multiperiod assembly system for $P=4$.

The assumption of this model is as follows:

(i) A percentage of components at each level are scrap.

(ii) The demand at each period is constant.

(iii) Ordering policy is POQ.

(iv) Lead time for each component is uncertainty.

(v) Shortage is allowed and it is partial backlogging.

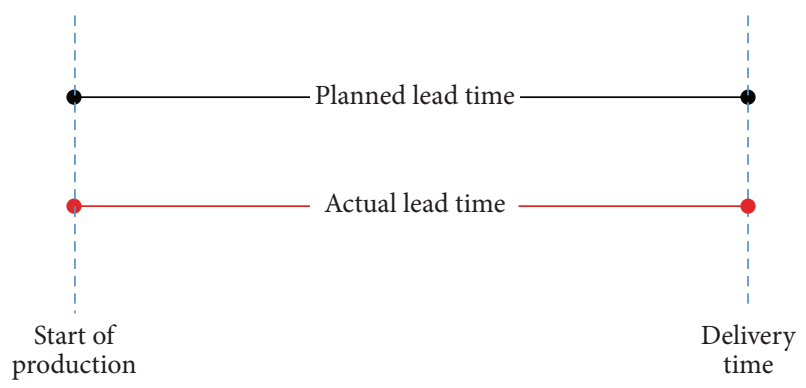

FIgURE 1: Planned lead time and actual lead time are the same.

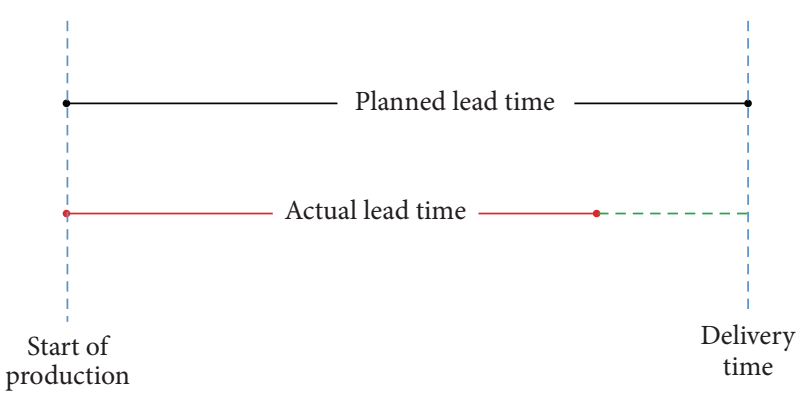

FIgURE 2: Planned lead time is bigger than actual.

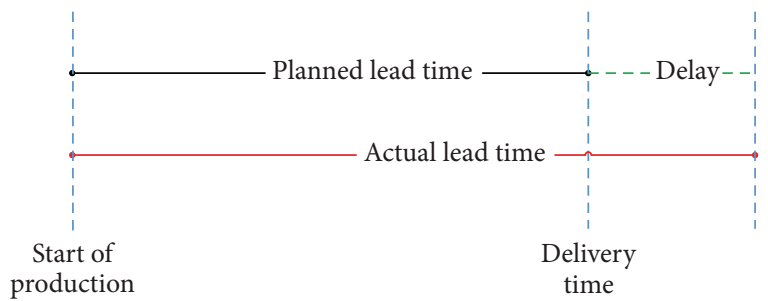

FIGURE 3: Planned lead time is smaller than actual lead time.

The aim is finding planned lead time for each component and periodicity $(P)$ for minimizing the sum of the holding costs for the components and backordering cost, lost sale cost, and holding cost for the finished product.

\section{Notation}

Notations are as follows:

$t, i, j:$ index of period's $t=1,2,3, \ldots$,

$N$ : total level of assembly system,

$m_{i j}$ : total number of components in level $i$ with uplevel $j$,

$A$ : fixed ordering cost,

$x_{0}$ : planned lead time in level 1 ,

$x_{i}$ : planned lead time for component $i$ in level 1 ,

$x_{i j k}$ : planned lead time of component $j$ in level $i$ with up-level $k$,

$h_{i j k}$ : unit holding cost of component $j$ in level $i$ per unit of time with up-level $k$,

$a_{i j k}$ : set of the required components to assemble component $j$ in level $i$ with up-level $k$, 
TABLE 1

\begin{tabular}{|c|c|c|c|c|}
\hline $\begin{array}{l}\text { Type of } \\
\text { system }\end{array}$ & Author(s) & Order policy & Criteria & Solution methods \\
\hline \multirow{9}{*}{ One-level } & Chu et al. (1993) [9] & Lot-for-lot & Holding and backlogging cost & Iterative algorithm \\
\hline & Proth et al. (1997) [24] & Lot-for-lot & Holding and backlogging cost & Heuristic algorithm \\
\hline & Dolgui et al. (2002) [25] & Lot-for-lot & Holding and backlogging cost & Markovian model \\
\hline & $\begin{array}{l}\text { Ould-Louly and Dolgui } \\
\text { (2004) [10] }\end{array}$ & Lot-for-lot & Holding and backlogging costs & $\begin{array}{l}\text { Markovian and Newsboy } \\
\text { model for a dynamical } \\
\text { multiperiod planning }\end{array}$ \\
\hline & Louly et al. (2008) [26] & Lot-for-lot & $\begin{array}{l}\text { Minimized holding cost with } \\
\text { keeping a high customer service } \\
\text { level }\end{array}$ & Optimization \\
\hline & $\begin{array}{l}\text { Louly and Dolgui (2011) } \\
\qquad[27]\end{array}$ & POQ & $\begin{array}{l}\text { holding, finished product } \\
\text { backlogging, and setup costs }\end{array}$ & Branch and Bound \\
\hline & Louly et al. (2012) [12] & POQ & Setup and holding costs & Optimization \\
\hline & Sadeghi et al. (2013) [13] & POQ & $\begin{array}{l}\text { Minimized fixed ordering, holding, } \\
\text { and backlogging costs }\end{array}$ & Optimization \\
\hline & Sadeghi et al. (2015) [19] & POQ & $\begin{array}{l}\text { Minimized fixed ordering, holding, } \\
\text { and backlogging costs }\end{array}$ & Optimization \\
\hline \multirow{7}{*}{ Two-level } & Yano (1987) [8] & Lot-for-lot & Sum of holding and tardiness costs & Nonlinear programming \\
\hline & $\begin{array}{l}\text { Tang and Grubbström } \\
\text { (2003) [28] }\end{array}$ & Lot-for-lot & $\begin{array}{l}\text { Stock-out and inventory holding } \\
\text { costs }\end{array}$ & $\begin{array}{l}\text { Laplace transform } \\
\text { procedure }\end{array}$ \\
\hline & Axsäter (2006) [29] & & & $\begin{array}{c}\text { Approximate } \\
\text { decomposition technique, } \\
\text { continuous distributions }\end{array}$ \\
\hline & Hnaien et al. (2009) [15] & Lot-for-lot & Holding and backlogging cost & $\begin{array}{l}\text { Genetic algorithm } \\
\text { optimization }\end{array}$ \\
\hline & Hnaien et al. (2010) [17] & Lot-for-lot & $\begin{array}{l}\text { Holding costs to maximize the } \\
\text { customer service level }\end{array}$ & Genetic algorithms \\
\hline & Sakiani et al. (2012) [16] & POQ & $\begin{array}{l}\text { Minimized holding cost and } \\
\text { maximized customer service }\end{array}$ & $\begin{array}{l}\text { NSGA-II algorithm, } \\
\text { multiobjective, tournament } \\
\text { selection }\end{array}$ \\
\hline & Sadeghi et al. (2015) [18] & POQ & $\begin{array}{l}\text { Minimized sum of fixed ordering, } \\
\text { holding, and backlogging costs }\end{array}$ & Optimization \\
\hline \multirow[b]{2}{*}{ Multi-Level } & Ammar et al. (2014) [22] & Lot-for-lot & $\begin{array}{l}\text { Holding, backlogging, and } \\
\text { inventory holding cost }\end{array}$ & $\begin{array}{l}\text { Simulation, mathematical } \\
\text { model, GA }\end{array}$ \\
\hline & Current paper & POQ & $\begin{array}{l}\text { Minimized expected fixed ordering, } \\
\text { holding, and partial backlogging } \\
\text { cost with a percentage of } \\
\text { components at each level are scrap }\end{array}$ & Optimization \\
\hline
\end{tabular}

TABle 2: An example of MRP for POQ policy $(P=4)$.

\begin{tabular}{lcccccccc}
\hline Period & 1 & 2 & 3 & 4 & 5 & 6 & 7 & 8 \\
\hline Demand & $\mathrm{D}$ & $\mathrm{D}$ & $\mathrm{D}$ & $\mathrm{D}$ & $\mathrm{D}$ & $\mathrm{D}$ & $\mathrm{D}$ & $\mathrm{D}$ \\
Initial inventory & 0 & 0 & 0 & 0 & 0 & 0 & 0 & 0 \\
Planned order receipts & $4 \mathrm{D}$ & 0 & 0 & 0 & $4 \mathrm{D}$ & 0 & 0 & 0 \\
\hline
\end{tabular}

$D$ : demand for final product at period $t$,

$h$ : unit holding cost for final product,

$b$ : unit backorder for final product,

$\widehat{B}$ : backlogging costs for each component in each period,

$B$ : lost sales for each component in each period, $\beta$ : the percentage of backordering which is backlogging,

$\alpha_{i}$ : the present of west for level $i$,

$l_{i j k}$ : actual lead time of component $j$ in level $i$ with parent $k$,

$P\left(l_{i j k}\right)$ : the probability distribution of lead time of component $j$ in level $i$ with parent $k$,

$\widehat{C}(x, P)$ : average of total cost in each period.

\section{Variables}

Variables are as follows:

$P$ : periodic order quantity,

$X$ : planned lead time for components $\left(x=\left(x_{0}\right.\right.$, $\left.x_{1}, x_{2}, \ldots\right)$ ). 


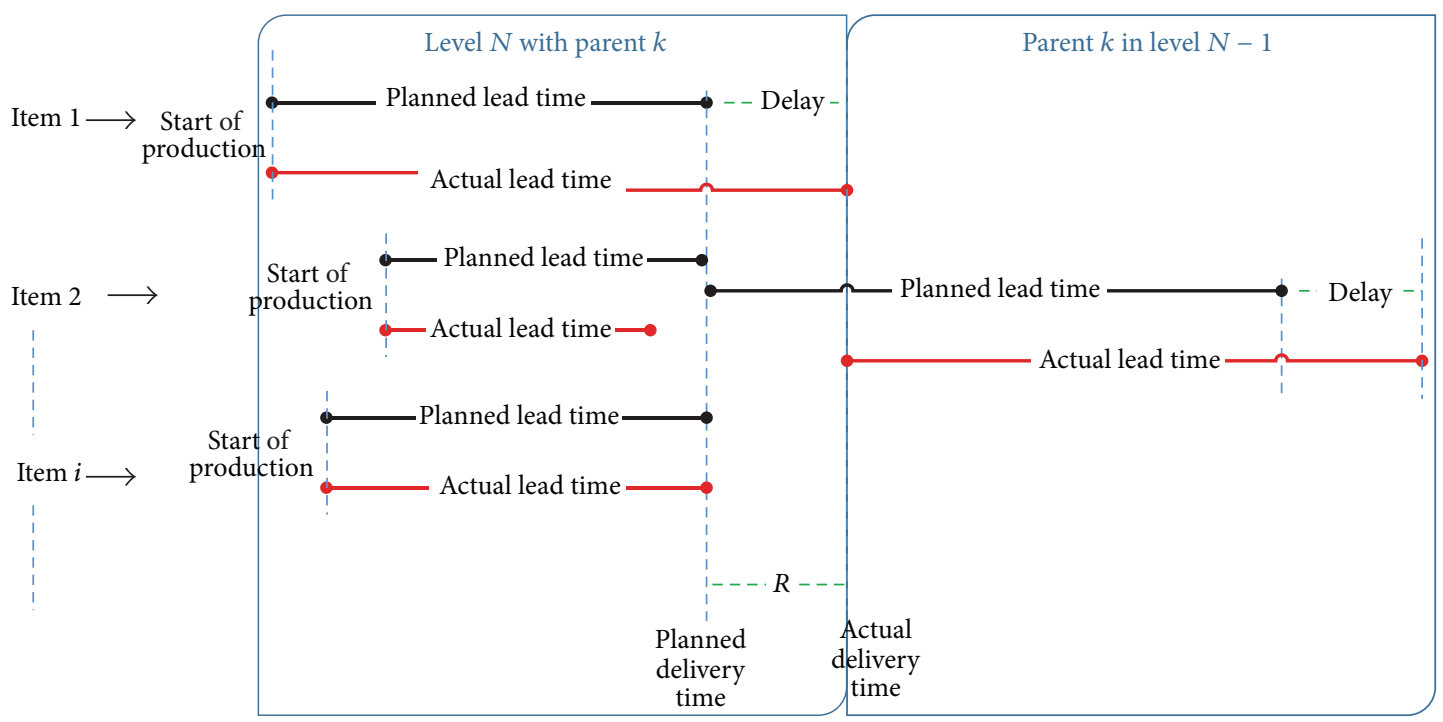

FIGURE 4: Schematic view of planned and actual lead time action on the sublevel $N$.

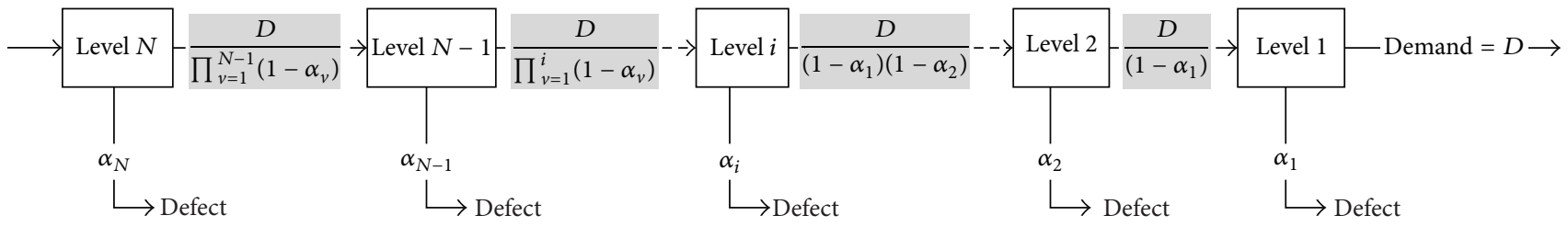

FIGURE 5: Percentage of waste for components at each level.

\section{Model Development}

Due to uncertain component's lead time, difference components on each sublevel do not arrive at the same time, so the components which arrive earlier than others should be held until all components arrive at this level. Difference between actual and planned lead time is used for finding the delivery time, and its value may be equal to zero or positive or negative. The largest difference between actual and planned lead time shows the latest arrived component. If $l_{i j k}$ is actual lead time and $x_{i j k}$ is planned lead time, then $R_{i j}=\operatorname{Max}_{k}\left(l_{i j k}-x_{i j k}\right)$ is the difference time with planned delivery time for level $i$. Figure 4 illustrates a schematic view of planned and actual lead time action on the same sublevel.

In this system, at each level, a percentage of components are scrap. Figure 5 shows the percentage of waste for components at each level.

According to Figures 4 and 6 , it is obvious that the components which arrive earlier than others should be held until all components arrive at this level. A percentage of components at this level are scrap. If $\alpha_{i}$ is a percentage of component's scrap at level $i$, then the cost for sublevel 1 to $N$ is as follows:

Cost for sublevel $N$ :

$$
\begin{aligned}
& \operatorname{Cost}\left(x_{N j}, P\right)=\frac{D \times P}{\prod_{q=1}^{N-1}\left(1-\alpha_{q}\right)} \\
& \quad \times\left[h_{N 1}\left(x_{N 1}+R_{N}-L_{N 1}\right)+h_{N 2}\left(x_{N 2}+R_{N}-L_{N 2}\right)\right.
\end{aligned}
$$

$$
\begin{aligned}
& \left.+\cdots+h_{N m_{N}}\left(x_{N m_{N}}+R_{N}-L_{N m_{N}}\right)\right] \\
& =\frac{D \times P}{\prod_{q=1}^{N-1}\left(1-\alpha_{q}\right)} \\
& \times \sum_{j=1}^{m_{N}}\left[h_{N j}\left(x_{N j}+R_{N}-L_{N j}\right) \mid L_{N j}-x_{N j} \leq R_{N}\right] .
\end{aligned}
$$

Cost for sublevel $i(i=2,3, \ldots, N-1)$ :

$$
\begin{aligned}
& \operatorname{Cost}_{i}\left(x_{i j}, P\right)=\frac{D \times P}{\prod_{q=1}^{i-1}\left(1-\alpha_{q}\right)} \times\left[h _ { i 1 , 1 } \left(x_{i 1,1}+R_{i, 1}\right.\right. \\
& \left.-R_{i+1,1}-L_{i 1,1}\right)+h_{i 2,1}\left(x_{i 2,1}+R_{i, 1}-R_{i+1,1}-L_{i 2,1}\right) \\
& \left.+\cdots+h_{i m_{i}, k}\left(x_{i m_{i}, k}+R_{i, m_{i}}-R_{i+1, m_{i}}-L_{i m_{i}, k}\right)\right] \\
& =\frac{D \times P}{\prod_{q=1}^{i-1}\left(1-\alpha_{q}\right)} \\
& \quad \times \sum_{j=1}^{m_{i}} \sum_{w=1}^{m_{i, j}}\left[h_{i j w}\left(x_{i j w}+R_{i, j}-R_{i+1, j}-L_{i j w}\right) \mid L_{i j w}\right. \\
& \left.-x_{i j w} \leq R_{i, j}-R_{i+1, j}\right] .
\end{aligned}
$$




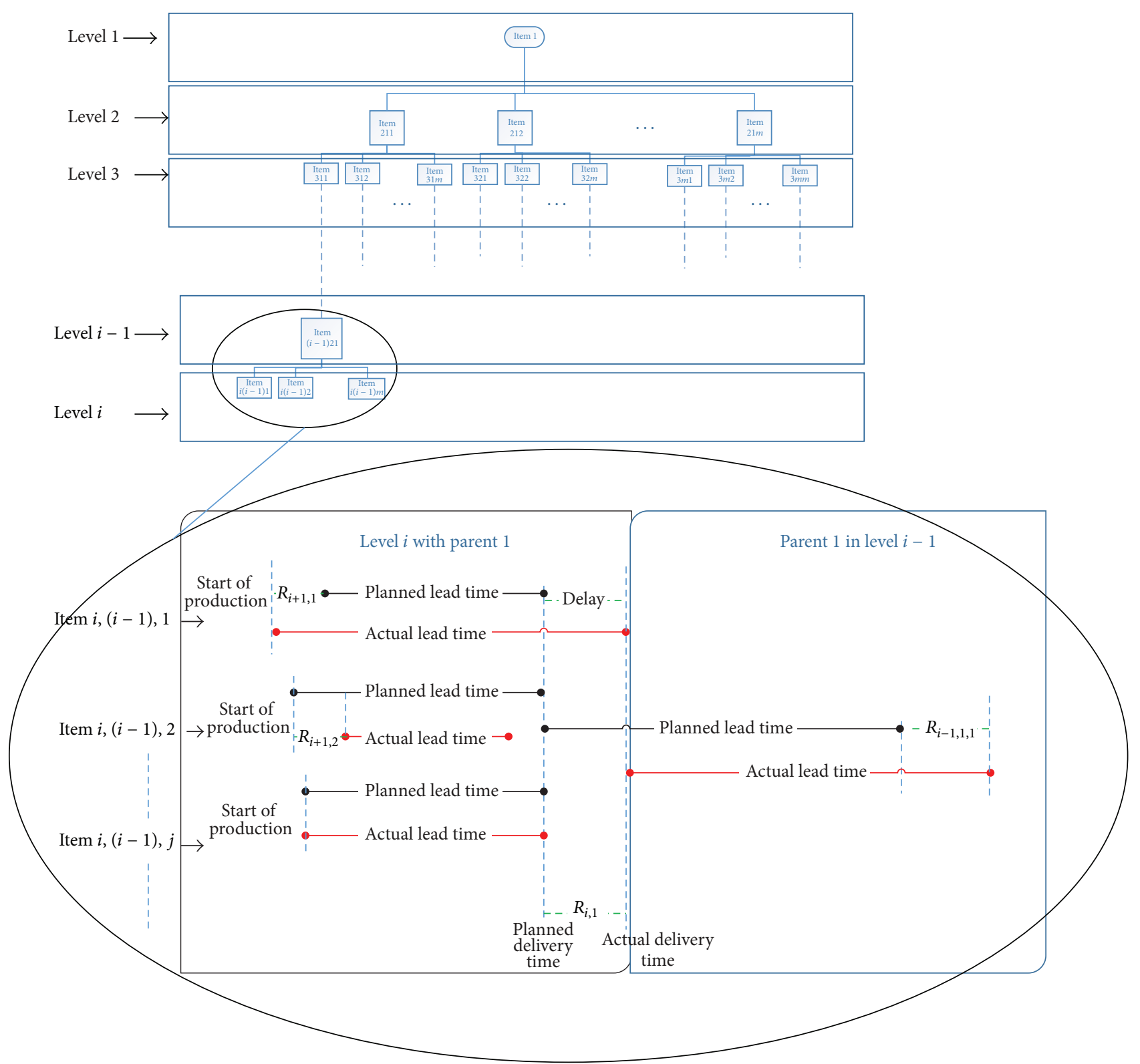

FIGURE 6: Schematic view of planned and actual lead time action on the sublevel $i$.

The total holding cost for $i(i=1,2, \ldots, N-1)$ can be formulated as

$$
\begin{aligned}
& \operatorname{Cost}\left(x_{i}, P\right)=\sum_{i=2}^{N-1} \frac{D \times P}{\prod_{q=1}^{i-1}\left(1-\alpha_{q}\right)} \\
& \quad \times \sum_{j=1}^{m_{i}} \sum_{w=1}^{m_{i, j}}\left[h_{i j w}\left(x_{i j w}+R_{i, j}-R_{i+1, j}-L_{i j w}\right) \mid L_{i j w}\right. \\
& \left.\quad-x_{i j w} \leq R_{i, j}\right]
\end{aligned}
$$

where $R_{i, j}=\operatorname{Max}_{w=1,2, \ldots, m_{i j}}\left(L_{i j w}-x_{i j w}+R_{i+1, j, w}\right)$.
By summarizing (1) and (3), total holding cost can be formulated as follows:

$$
\begin{aligned}
& \operatorname{Cost}_{1}\left(x_{i}, P\right)=\sum_{i=1}^{N-1} \frac{D \times P}{\prod_{q=1}^{i-1}\left(1-\alpha_{q}\right)} \\
& \quad \times \sum_{j=1}^{m_{i}} \sum_{w=1}^{m_{i, j}}\left[h_{i j w}\left(x_{i j w}+R_{i, j}-R_{i+1, j}-L_{i j w}\right) \mid L_{i j w}\right. \\
& \left.-x_{i j w} \leq R_{i, j}\right]
\end{aligned}
$$

where

$$
R_{i, j}=\operatorname{Max}_{w=1,2, \ldots, m_{i j}}\left(L_{i j w}-x_{i j w}+R_{i+1, j, w}\right), \quad R_{N+1, j}=0 .
$$




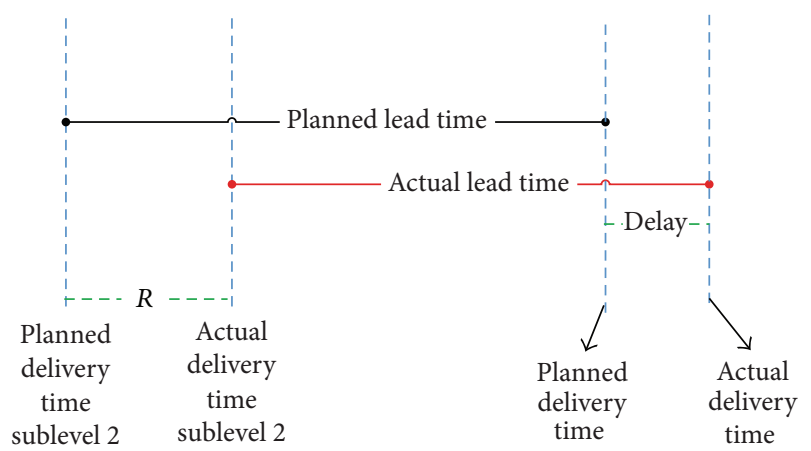

FIGURE 7: Schematic view of planned and actual lead time action on level one.

After all components are produced at level $i+1$, the component at level $i$ will be started. If at a certain level, a job is not received at the expected time, a delay is incurred at the delivery of production at this level and results in backorders of the finished product. In this case, it is assumed that a fixed percentage of the shortage is backlogged and other sales are lost. In this level, if production is carried out before delivery time, product should be held until delivery time and then sent to the customer and if production is carried out after delivery time, the products are sent to the customer by delay. Figure 7 illustrates a schematic view of planned and actual lead time action on level one.

Before producing a multilevel production system, the production system should be scheduled and planned lead time for all components should be determined. At each production cycle, all order is produced for $P$ period; then at each production cycle, $P \times D$ units product is produced. When production product is initiated, actual lead time may be equal or bigger than or small than planned lead time. Therefore, to calculate the cost, these three stats should be considered.

State 1. If planned delivery time is equal to actual delivery time for first level, then $P \times D$ units of product are achieved according to planned schedule and sent to the customer period by period (Figure 8). At each period, $D$ unit of this product is sent to the customer and others are held. A percentage of components at this level are scrap. If $\alpha_{1}$ is a percentage of component's scrap in this level, then the cost for this state is as follows:

$$
\begin{aligned}
\operatorname{Cost}_{2}(x, P) & \\
= & \frac{1}{1-\alpha_{1}}[(P-1) \times D+(P-2) \times D+\cdots+D] \\
& \times P\left(L_{0}=x_{0}\right) \\
= & \frac{P \times(P-1)}{2 \times\left(1-\alpha_{1}\right)} \times h \times D \times P\left(L_{0}=x_{0}-R\right) .
\end{aligned}
$$

State 2. If planned delivery time is greater than actual delivery time for first level, then $P \times D$ units of product are achieved before planned schedule, so all products should be held until planned delivery time and then sent to customer period by period (Figure 9). Therefore, the cost for this state is as follows:

$$
\begin{gathered}
\operatorname{Cost}_{3}(x, P)=\frac{1}{\left(1-\alpha_{1}\right)}\left[h \times D \times P \times\left(x_{0}-L_{0}+R\right)\right. \\
\left.+\frac{P \times(P-1)}{2} \times h \times D\right] \times P\left(L_{0}<x_{0}-R\right) .
\end{gathered}
$$

State 3. If planned delivery time is smaller than actual delivery time for first level, then $P \times D$ units of product are achieved after planned schedule; then the customer's order is carried out with delay and backordering is accrued (Figure 10). A fixed percentage of the shortage is backlogged and other sales are lost. Therefore, the cost for this state is as follows:

$$
\begin{aligned}
& \operatorname{Cost}_{4}(x, P)=\frac{1}{\left(1-\alpha_{1}\right)} \times\left[h \times D \times P \times\left(x_{0}-L_{0}+R\right)\right. \\
& +\frac{\left(P+x_{0}-L_{0}-R\right) \times\left(P-1+x_{0}-L_{0}-R\right)}{2} \times h \\
& \times D] \times P\left(A L_{0}>P L_{0}-R\right)+\frac{1}{\left(1-\alpha_{1}\right)} \\
& \times\left[\frac{\left(L_{0}-x_{0}+R\right) \times\left(L_{0}-x_{0}+R+1\right)}{2} \times \alpha \times \widehat{B}\right. \\
& \times D] \times P\left(A L_{0}>P L_{0}-R\right)+\frac{1}{\left(1-\alpha_{1}\right)} \\
& \times\left[\frac{\left(L_{0}-x_{0}+R\right) \times\left(L_{0}-x_{0}+R+1\right)}{2} \times(1-\alpha)\right. \\
& \times B \times D] \times P\left(L_{0}>x_{0}-R\right) .
\end{aligned}
$$

Total costs are expressed as follows:

$$
\begin{aligned}
& \text { Cost }(x, P)=\text { Start up cost }+\operatorname{Cost}_{1}(x, P)+\operatorname{Cost}_{2}(x, \\
& P)+\operatorname{Cost}_{3}(x, P)+\operatorname{Cost}_{4}(x, P)=A \\
& +\sum_{i=1}^{N-1} \frac{D \times P}{\prod_{q=1}^{i-1}\left(1-\alpha_{q}\right)} \\
& \times \sum_{j=1}^{m_{i}} \sum_{w=1}^{m_{i, j}}\left[h_{i j w}\left(x_{i j w}+R_{i, j}-R_{i+1, j}-L_{i j w}\right) \mid L_{i j w}\right. \\
& \left.-x_{i j w} \leq R_{i, j}\right]+\frac{1}{\left(1-\alpha_{1}\right)} \times\left[h \times D \times P \times\left(x_{0}-L_{0}\right.\right. \\
& +R)+\frac{\left(P+x_{0}-L_{0}-R\right) \times\left(P-1+x_{0}-L_{0}-R\right)}{2} \\
& \times h \times D] \times P\left(A L_{0}>P L_{0}-R\right)+\frac{1}{\left(1-\alpha_{1}\right)}
\end{aligned}
$$




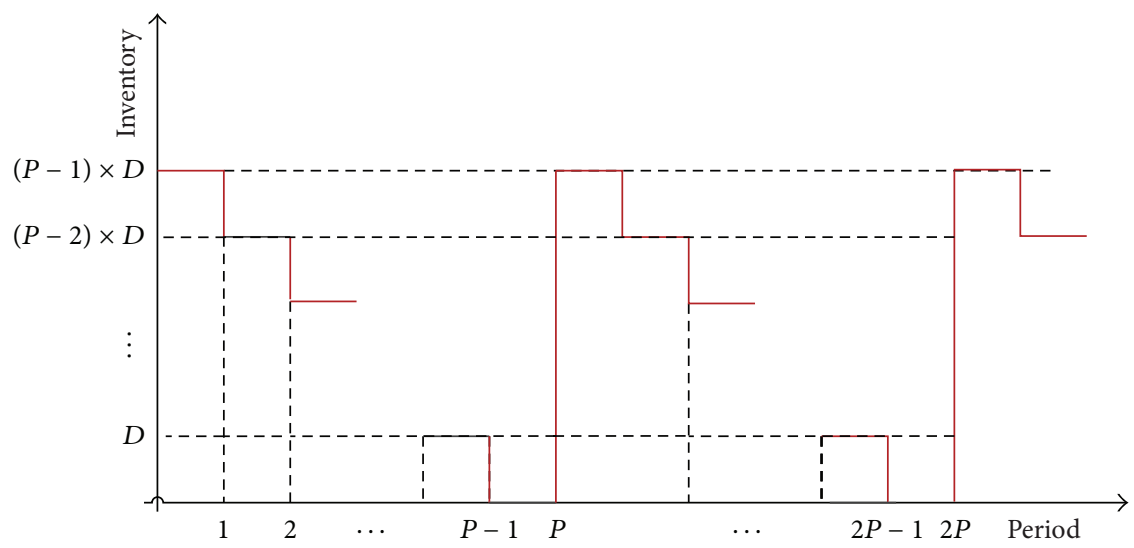

FIGURE 8: Planning problem when planned delivery time is equal to actual delivery time.

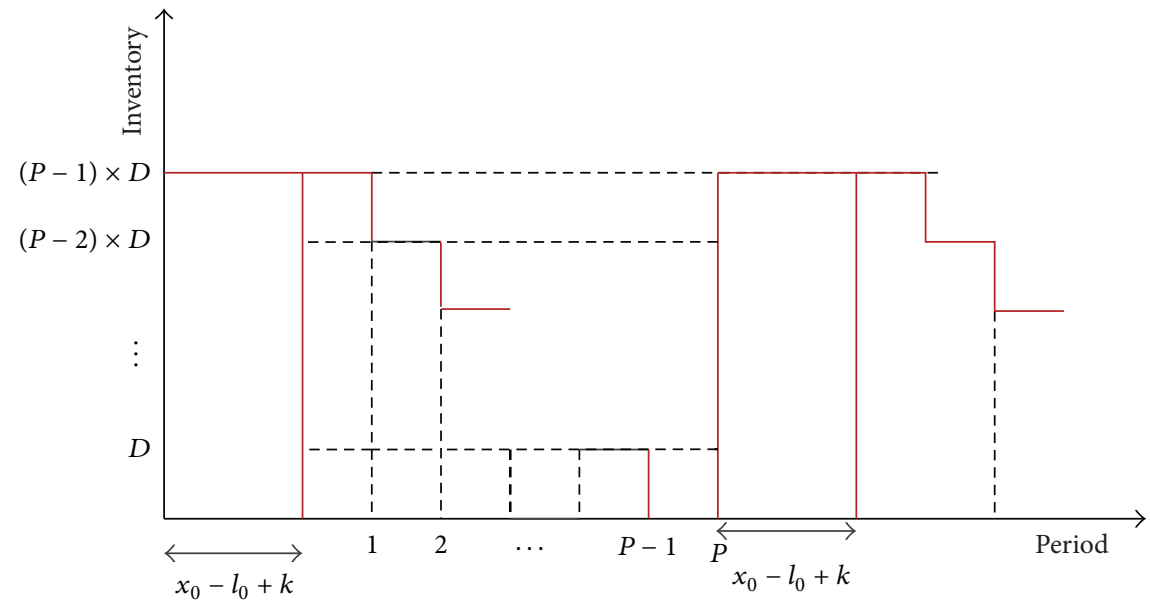

FIGURE 9: Planned lead time is bigger than the actual lead time for first level.

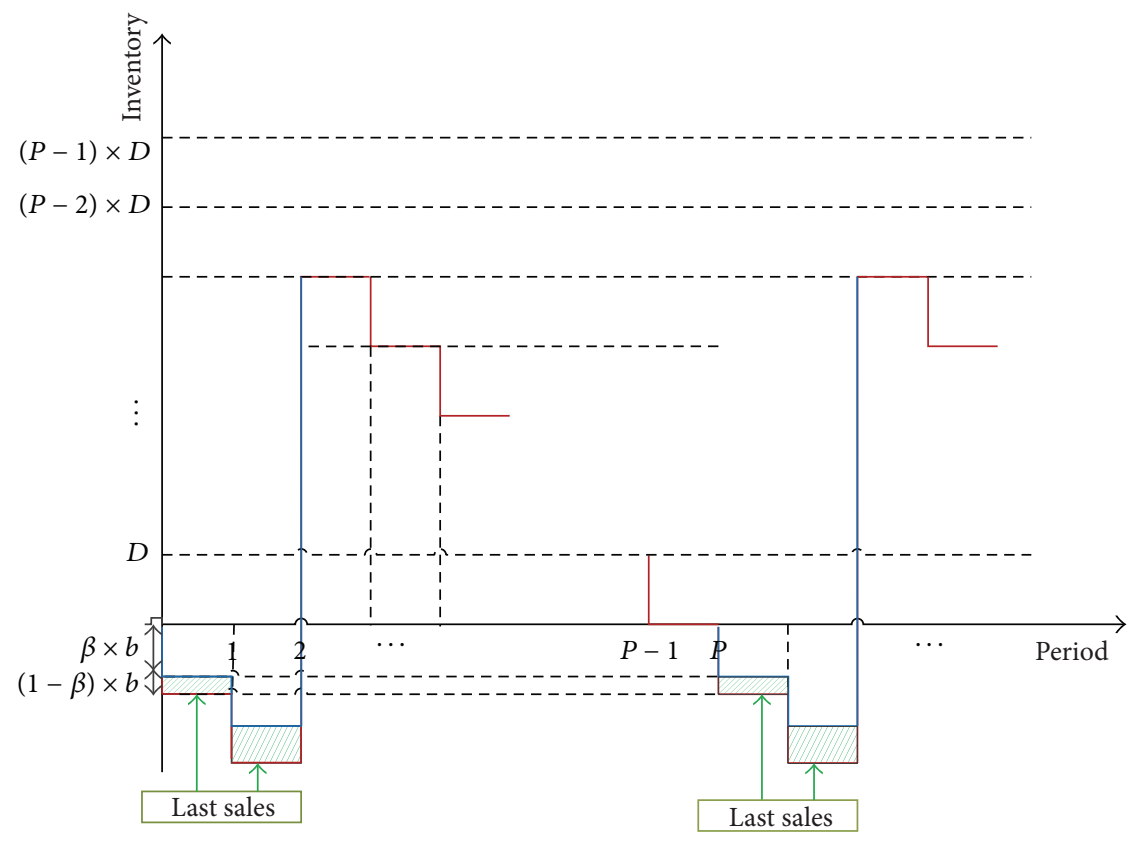

Figure 10: Planned lead time is smaller than to actual lead time for first level. 


$$
\begin{aligned}
& \times\left[\frac{\left(L_{0}-x_{0}+R\right) \times\left(L_{0}-x_{0}+R+1\right)}{2} \times \alpha \times \widehat{B}\right. \\
& \times D] \times P\left(A L_{0}>P L_{0}-R\right)+\frac{1}{\left(1-\alpha_{1}\right)} \\
& \times\left[\frac{\left(L_{0}-x_{0}+R\right) \times\left(L_{0}-x_{0}+R+1\right)}{2} \times(1-\alpha)\right. \\
& \times B \times D] \times P\left(L_{0}>x_{0}-R\right) .
\end{aligned}
$$

By simplifying (9), the total cost is as follows:

$$
\begin{aligned}
& \operatorname{Cos}(x, P)=A+\left[\frac{P(P-1)}{2\left(1-\alpha_{1}\right)} h \times D+\frac{h \times P \times D}{\left(1-\alpha_{1}\right)}\right. \\
& \quad \times E\left(x_{0}-L_{0}-R\right)+P \times D \\
& \quad \times \sum_{i=1}^{N} \frac{\sum_{j=1}^{m_{i}} \sum_{w=1}^{m_{i j}} h_{i j k} a_{i j w}\left(x_{i j w}+R_{i, j}-L_{i j w}-k_{i+1, j}\right)}{\prod_{v}^{i}\left(1-\alpha_{v}\right)} \\
& +\frac{D}{2 \times\left(1-\alpha_{1}\right)} \times(h) \\
& \times\left[\left(l_{0}-x_{0}+R\right)^{2}+\left(l_{0}-x_{0}+R\right)\right] \times P\left(l_{0} \geq x_{0}-R\right) \\
& +\beta \times \frac{D}{2 \times\left(1-\alpha_{1}\right)} \times(\widehat{B}) \\
& \times\left[\left(l_{0}-x_{0}+R\right)^{2}+\left(l_{0}-x_{0}+R\right)\right] \times P\left(l_{0} \geq x_{0}-R\right) \\
& +(1-\beta) \times \frac{D}{2 \times\left(1-\alpha_{1}\right)} \times(B) \\
& \times\left[\left(l_{0}-x_{0}+R\right)^{2}+\left(l_{0}-x_{0}+R\right)\right] \\
& \left.\times\left(l_{0} \geq x_{0}-R\right)\right] .
\end{aligned}
$$

The cost function is a random variable; therefore, to study the considered multiperiod problem, explicit closed forms should be obtained for the average cost and the average number of shortages on the infinite horizon according to the following expressions:

$$
\widehat{C}(x, P)=\lim _{r \rightarrow \infty} \sum_{t=1}^{r} \frac{C(x, P)}{P \times r} \Longrightarrow .
$$

Then by using (10), the expressed unit cost will be as follows:

$$
\begin{aligned}
& \operatorname{Cost}(x, P)=\frac{A}{P}+\left[\frac{(P-1)}{2\left(1-\alpha_{1}\right)} h \times D+\frac{h \times D}{\left(1-\alpha_{1}\right)}\right. \\
& \times E\left(x_{0}-L_{0}-R\right)+D \\
& \times \sum_{i=1}^{N} \frac{\sum_{j=1}^{m_{i}} \sum_{w=1}^{m_{i j}} h_{i j k} a_{i j w}\left(x_{i j w}+R_{i, j}-L_{i j w}-R_{i+1, j}\right)}{\prod_{v}^{i}\left(1-\alpha_{v}\right)}
\end{aligned}
$$

$$
\begin{aligned}
& +\frac{D}{2 \times P \times\left(1-\alpha_{1}\right)} \times(h) \\
& \times\left[\left(l_{0}-x_{0}+R\right)^{2}+\left(l_{0}-x_{0}+R\right)\right] \times P\left(l_{0} \geq x_{0}-R\right) \\
& +\beta \times \frac{D}{2 \times P \times\left(1-\alpha_{1}\right)} \times(\widehat{B}) \\
& \times\left[\left(l_{0}-x_{0}+R\right)^{2}+\left(l_{0}-x_{0}+R\right)\right] \times P\left(l_{0} \geq x_{0}-R\right) \\
& +(1-\beta) \times \frac{D}{2 \times P \times\left(1-\alpha_{1}\right)} \times(B) \\
& \times\left[\left(l_{0}-x_{0}+R\right)^{2}+\left(l_{0}-x_{0}+R\right)\right] \\
& \left.\times P\left(l_{0} \geq x_{0}-R\right)\right] .
\end{aligned}
$$

According to (12), actual lead time is defined for one period, but planned lead time is defined for $P$ period. Then planned lead time for one period is equal to $x_{P} / P$, where $x_{P}$ is planned lead-time $P$ period.

The total cost should be minimized, to find the optimal solution; the function cost is separated into three parts comprising constant, linear, and nonlinear parts as shown below:

Constant part:

$$
\left([\widehat{\operatorname{Cost}}(P L, P)]_{1}\right)=\frac{A}{P}+\frac{(P-1)}{2\left(1-\alpha_{1}\right)} h \times D .
$$

Linear part:

$$
\begin{aligned}
& \left([\widehat{\operatorname{Cost}}(P L, P)]_{2}\right)=D \\
& \quad \times \sum_{i=1}^{N} \frac{\sum_{j=1}^{m_{i}} \sum_{w=1}^{m_{i j}} h_{i j k} a_{i j w}\left(x_{i j w}+R_{i, j}-L_{i j w}-R_{i+1, j}\right)}{\prod_{v}^{i}\left(1-\alpha_{v}\right)} .
\end{aligned}
$$

Nonlinear part:

$$
\begin{aligned}
& \left([\widehat{\operatorname{Cost}}(P L, P)]_{3}\right) \\
& =\frac{h \times D}{\left(1-\alpha_{1}\right)} \times E\left(x_{0}-L_{0}-R\right)+\frac{D}{2 \times P \times\left(1-\alpha_{1}\right)} \\
& \quad \times(h) \times\left[\left(l_{0}-x_{0}+R\right)^{2}+\left(l_{0}-x_{0}+R\right)\right] \\
& \quad \times P\left(l_{0} \geq x_{0}-R\right)+\beta \times \frac{D}{2 \times P \times\left(1-\alpha_{1}\right)} \times(\widehat{B}) \\
& \quad \times\left[\left(l_{0}-x_{0}+R\right)^{2}+\left(l_{0}-x_{0}+R\right)\right] \\
& \quad \times P\left(l_{0} \geq x_{0}-R\right)+(1-\beta) \times \frac{D}{2 \times P \times\left(1-\alpha_{1}\right)} \\
& \quad \times(B) \times\left[\left(l_{0}-x_{0}+R\right)^{2}+\left(l_{0}-x_{0}+R\right)\right] \\
& \quad \times P\left(l_{0} \geq x_{0}-R\right) .
\end{aligned}
$$


The part is not dependent on lead time and linear parts depended on the value of the lead time in the level $i(i=$ $2,3, \ldots, N)$ and it is clear that optimal solution is $x_{i j w}=$ $-R_{i, j}+L_{i j w}+R_{i+1, j}$.

The main parts of the cost function are nonlinear parts. The part of the cost is convex; hence the optimal solution is computable for this part.
Theorem 1. Linear part is minimalized when $x_{i j w}$ is equal to medium of $-R_{i, j}+L_{i j w}+R_{i+1, j}$. Consider

$$
\begin{aligned}
D & \times \sum_{i=1}^{N} \frac{\sum_{j=1}^{m_{i}} \sum_{w=1}^{m_{i j}} h_{i j k} a_{i j w}\left(x_{i j w}+R_{i, j}-L_{i j w}-R_{i+1, j}\right)}{\prod_{v}^{i}\left(1-\alpha_{v}\right)} \\
= & D \times \sum_{i=1}^{N} \frac{\sum_{j=1}^{m_{i}} \sum_{w=1}^{m_{i j}} h_{i j k} a_{i j w} \int\left(x_{i j w}+R_{i, j}-L_{i j w}-R_{i+1, j}\right) \times f\left(L_{i j w}\right) d_{L_{i j w}}}{\prod_{v}^{i}\left(1-\alpha_{v}\right)} \\
= & D \times \sum_{i=1}^{N} \frac{\sum_{j=1}^{m_{i}} \sum_{w=1}^{m_{i j}} h_{i j k} a_{i j w} \int\left(x_{i j w}+R_{i, j}-R_{i+1, j}\right) \times f\left(L_{i j w}\right) d_{L_{i j w}}}{\prod_{v}^{i}\left(1-\alpha_{v}\right)}-D \\
& \times \sum_{i=1}^{N} \frac{\sum_{j=1}^{m_{i}} \sum_{w=1}^{m_{i j}} h_{i j k} a_{i j w} \int\left(L_{i j w}\right) \times f\left(L_{i j w}\right) d_{L_{i j w}}}{\prod_{v}^{i}\left(1-\alpha_{v}\right)} \\
= & D \times \sum_{i=1}^{N} \frac{\sum_{j=1}^{m_{i}} \sum_{w=1}^{m_{i j}} h_{i j k} a_{i j w} \times\left(x_{i j w}+R_{i, j}-k_{i+1, j}\right)}{\prod_{v}^{i}\left(1-\alpha_{v}\right)}-D \times \sum_{i=1}^{N} \frac{\sum_{j=1}^{m_{i}} \sum_{w=1}^{m_{i j}} h_{i j k} a_{i j w} \times E\left[L_{i j w}\right]}{\prod_{v}^{i}\left(1-\alpha_{v}\right)} \\
= & D \times \sum_{i=1}^{N} \frac{\sum_{j=1}^{m_{i}} \sum_{w=1}^{m_{i j}} h_{i j k} a_{i j w} \times\left(x_{i j w}+R_{i, j}-R_{i+1, j}-E\left[L_{i j w}\right]\right)}{\prod_{v}^{i}\left(1-\alpha_{v}\right)} .
\end{aligned}
$$

Equation (16) is minimalized when $x_{i, j, w}$ is equal to medium of $-R_{i, j}+L_{i j w}+R_{i+1, j}$.

Theorem 2. Nonlinear part $\left([\widehat{\operatorname{Cost}}(P L, P)]_{3}\right)$ of the objective function is convex. Consider

$$
\begin{aligned}
& \frac{\partial[\widehat{\operatorname{Cost}}(x, P)]_{3}}{\partial x_{0}} \\
& =\frac{h \times D}{\left(1-\alpha_{1}\right)}-\frac{D}{P \times\left(1-\alpha_{1}\right)} \\
& \quad \times(h+\alpha \times \widehat{B}+(1-\alpha) \times B) \\
& \quad \times\left(L_{0}-x_{0}+R+1\right) P\left(L_{0} \geq x_{0}-R\right) \\
& \frac{\partial^{2}[\widehat{\operatorname{Cost}}(x, P)]_{3}}{\partial x^{2}} \\
& =\frac{D}{P \times\left(1-\alpha_{1}\right)} \times(h+\alpha \times \widehat{B}+(1-\alpha) \times B) \\
& \quad \times P\left(L_{0} \geq x_{0}-R\right) .
\end{aligned}
$$

Equation (18) is positive; then objective function is strictly convex.
The total cost equation $\widehat{C}(x, P)$ is convex; therefore, to find the optimal solution, the equation $\partial[\widehat{\operatorname{Cost}}(x, P)]_{3} / \partial x=0$ is used. Consider

$$
\begin{aligned}
\frac{\partial[\widehat{\operatorname{Cos}}(x, P)]_{3}}{\partial x_{0}} & \\
= & \frac{h \times D}{\left(1-\alpha_{1}\right)}-\frac{D}{P \times\left(1-\alpha_{1}\right)} \\
& \quad \times(h+\alpha \times \widehat{B}+(1-\alpha) \times B) \\
& \quad \times\left(L_{0}-x_{0}+R+1\right) P\left(L_{0} \geq x_{0}-R\right)=0 \Longrightarrow \\
\left(L_{0}-\right. & \left.x_{0}+R+1\right) P\left(L_{0} \geq x_{0}-R\right) \\
= & \frac{h \times P}{(h+\alpha \times \widehat{B}+(1-\alpha) \times B)} .
\end{aligned}
$$

To find $P$, the values $1,2, \ldots$ are utilized to obtain the total cost by (12) and the optimal value of $x$.

\section{Numerical Example}

Let us present an example with two levels and three components in sublevel 2. Assuming that the distribution of the 
component's lead time is uniform, then the value of the lead time, unit holding costs for all components, ordering cost, and backordering cost is shown in Table 3.

Demand of this product for each period is constant and equal to 20 units, setup cost is 100 units, percentage of backordering is $80 \%$, and others are lost sales.

According to (16), the optimal solution for planned lead time for level 2 is as follows:

$$
\begin{aligned}
& x_{1}+R=E\left[L_{1}\right]=4 . \\
& x_{2}+R=E\left[L_{2}\right]=3.5 . \\
& x_{3}+R=E\left[L_{3}\right]=4.5 .
\end{aligned}
$$

Consider $P=1$.

Step 1. Find planned lead time for first level by (19):

$$
\begin{aligned}
& \left(L_{0}-x_{0}+R+1\right) P\left(L_{0} \geq x_{0}-R\right) \\
& =\frac{h \times P}{(h+\alpha \times \widehat{B}+(1-\alpha) \times B)} \\
& \quad=\frac{15 \times 1}{(15+0.8 \times 5+0.2 \times 4)}=0.757576 \Longrightarrow \\
& \int_{x_{0}-R}^{10}\left(L_{0}-x_{0}+R+1\right) \frac{1}{8} d\left(L_{0}\right)=0.757576 \Longrightarrow \\
& \left(x_{0}-R\right)^{2}-22 \times\left(x_{0}-R\right)+95.75757=0 \Longrightarrow \\
& \left(x_{0}-R\right)=7.37681 \Longrightarrow \\
& x_{0}=7.37681+R .
\end{aligned}
$$

Step 2. Calculate cost by (12):

$$
\begin{aligned}
& \widehat{\operatorname{Cost}}(x, 1)=\frac{100}{1}+\left[\frac{15 \times 10}{(1-0.02)} \times(7.377681-6)\right. \\
& +\frac{10 \times 1}{(1-0.03) \times(1-0.02)} \\
& \times \sum_{i=1}^{m}\left[h_{i}\left(x_{i}+R-L_{i}\right) \mid L_{i}-x_{i} \leq R\right] \\
& \cdot \frac{10}{1 \times 2 \times(1-0.02)} \\
& \times(15+0.8 \times 5+(1-0.8) \times 4) \\
& \times\left[\left(L_{0}-7.377681\right)^{2}+\left(L_{0}-7.377681\right)\right] \\
& \left.\times P\left(L_{0} \geq x_{0}-R\right)\right]=\frac{100}{1}+\left[\frac{15 \times 10}{(1-0.02)}\right. \\
& \times(7.377681-6)+\frac{10 \times 1}{(1-0.03) \times(1-0.02)} \\
& \times(5 \times 0.25+3 \times 0.375+2 \times 0.375)
\end{aligned}
$$

$$
\begin{aligned}
& \frac{10}{1 \times 2 \times(1-0.02)} \\
& \times(15+0.8 \times 5+(1-0.8) \times 4) \times 1.181141] \\
& =463.0628 .
\end{aligned}
$$

Consider $P=2$.

Step 1. Find planned lead time for first level by (19):

$$
\begin{aligned}
& \left(L_{0}-x_{0}+R+1\right) P\left(L_{0} \geq x_{0}-R\right) \\
& =\frac{h \times P}{(h+\alpha \times \widehat{B}+(1-\alpha) \times B)} \\
& \quad=\frac{15 \times 2}{(15+0.8 \times 5+0.2 \times 4)}=1.515152 \Longrightarrow \\
& \int_{x_{0}-R}^{10}\left(L_{0}-x_{0}+R+1\right) \frac{1}{8} d\left(L_{0}\right)=1.515152 \Longrightarrow \\
& \left(x_{0}-R\right)^{2}-22 \times\left(x_{0}-R\right)+107.8788=0 \Longrightarrow \\
& \left(x_{0}-R\right)=5.975815 \Longrightarrow \\
& x_{0}=5.975815+R .
\end{aligned}
$$

Step 2. Calculate cost by (12):

$$
\begin{aligned}
& \widehat{\operatorname{Cost}}(x, 1)=\frac{100}{2}+\left[\frac{(2-1)}{2 \times(1-0.02)} \times 15 \times 10\right. \\
& +\frac{15 \times 10}{(1-0.02)} \times(5.975815-6) \\
& +\frac{10 \times 2}{(1-0.03) \times(1-0.02)} \\
& \times \sum_{i=1}^{m}\left[h_{i}\left(x_{i}+R-L_{i}\right) \mid L_{i}-x_{i} \leq R\right] \\
& +\frac{10}{2 \times 2 \times(1-0.02)} \\
& \times(15+0.8 \times 5+(1-0.8) \times 4) \\
& \times\left[\left(L_{0}-5.975815\right)^{2}+\left(L_{0}-5.975815\right)\right] \\
& \left.\times P\left(L_{0} \geq x_{0}-R\right)\right]=\frac{100}{2}+\left[\frac{(2-1)}{2 \times(1-0.02)} \times 15\right. \\
& \times 10+\frac{15 \times 10}{(1-0.02)} \times(5.975815-6) \\
& +\frac{10 \times 2}{(1-0.03) \times(1-0.02)} \\
& \times(5 \times 0.25+3 \times 0.375+2 \times 0.375)
\end{aligned}
$$


TABLE 3: Input parameters for this example.

\begin{tabular}{lcccc}
\hline Level & Distribution & Parameters & Holding cost & \multicolumn{2}{c}{ Partial backlogging } \\
\hline 1 & Uniform & $(2,10)$ & 15 & 5 \\
2 & Uniform & $(3,5)$ & 5 & - \\
2 & Uniform & $(2,5)$ & 3 & - \\
2 & Uniform & $(3,6)$ & 2 & - \\
\hline
\end{tabular}

$$
\begin{aligned}
& +\frac{10}{2 \times 2 \times(1-0.02)} \\
& \times(15+0.8 \times 5+(1-0.8) \times 4) \times 3.727459] \\
& =376.8515 .
\end{aligned}
$$

Consider $P=3$.

Step 1. Find planned lead time for first level by (19):

$$
\begin{aligned}
& \left(L_{0}-x_{0}+R+1\right) P\left(L_{0} \geq x_{0}-R\right) \\
& =\frac{h \times P}{(h+\alpha \times \widehat{B}+(1-\alpha) \times B)} \\
& \quad=\frac{15 \times 3}{(15+0.8 \times 5+0.2 \times 4)}=2.272727 \Longrightarrow \\
& \int_{x_{0}-R}^{10}\left(L_{0}-x_{0}+R+1\right) \frac{1}{8} d\left(L_{0}\right)=2.272727 \Longrightarrow \\
& \left(x_{0}-R\right)^{2}-22 \times\left(x_{0}-R\right)+83.63636=0 \Longrightarrow \\
& \left(x_{0}-R\right)=4.88742 \Longrightarrow \\
& x_{0}=4.88742+R .
\end{aligned}
$$

Step 2. Calculate cost by (12):

$$
\begin{aligned}
& \widehat{\operatorname{Cost}}(x, 3)=\frac{100}{3}+\left[\frac{(3-1)}{2 \times(1-0.02)} \times 15 \times 10\right. \\
& +\frac{15 \times 10}{(1-0.02)} \times(5.975815-6) \\
& +\frac{10 \times 3}{(1-0.03) \times(1-0.02)} \\
& \times \sum_{i=1}^{m}\left[h_{i}\left(x_{i}+R-L_{i}\right) \mid L_{i}-x_{i} \leq R\right] \\
& +\frac{10}{3 \times 2 \times(1-0.02)} \\
& \times(15+0.8 \times 5+(1-0.8) \times 4) \\
& \times\left[\left(L_{0}-5.975815\right)^{2}+\left(L_{0}-5.975815\right)\right]
\end{aligned}
$$

$$
\begin{aligned}
& \left.\times P\left(L_{0} \geq x_{0}-R\right)\right]=\frac{100}{3}+\left[\frac{(3-1)}{2 \times(1-0.02)} \times 15\right. \\
& \times 10+\frac{15 \times 10}{(1-0.02)} \times(5.975815-6) \\
& +\frac{10 \times 3}{(1-0.03) \times(1-0.02)} \\
& \times(5 \times 0.25+3 \times 0.375+2 \times 0.375) \\
& +\frac{10}{3 \times 2 \times(1-0.02)} \\
& \times(15+0.8 \times 5+(1-0.8) \times 4) \times 7.201781] \\
& =247.8279 .
\end{aligned}
$$

Consider $P=4$.

Step 1. Find planned lead time for first level by (19):

$$
\begin{aligned}
& \left(L_{0}-x_{0}+R+1\right) P\left(L_{0} \geq x_{0}-R\right) \\
& =\frac{h \times P}{(h+\alpha \times \widehat{B}+(1-\alpha) \times B)} \\
& \quad=\frac{15 \times 3}{(15+0.8 \times 5+0.2 \times 4)}=3.030303 \Longrightarrow \\
& \int_{x_{0}-R}^{10}\left(L_{0}-x_{0}+R+1\right) \frac{1}{8} d\left(L_{0}\right)=3.030303 \Longrightarrow \\
& \left(x_{0}-R\right)^{2}-22 \times\left(x_{0}-R\right)+71.51515=0 \Longrightarrow \\
& \left(x_{0}-R\right)=3.965453 \Longrightarrow \\
& x_{0}=3.965453+R .
\end{aligned}
$$

Step 2. Calculate cost by (12):

$$
\begin{aligned}
& \widehat{\operatorname{Cost}}(P L, 4)=\frac{100}{4}+\left[\frac{(4-1)}{2 \times(1-0.02)} \times 15 \times 10\right. \\
& +\frac{15 \times 10}{(1-0.02)} \times(5.975815-6) \\
& +\frac{10 \times 4}{(1-0.03) \times(1-0.02)}
\end{aligned}
$$


TABLE 4: Total cost.

\begin{tabular}{lcccc}
\hline$P$ & 1 & 2 & 3 & 4 \\
\hline Cost & 463.0628 & 376.8515 & $\mathbf{2 4 7 . 8 2 7 9}$ & 288.8142 \\
& $\searrow$ & $\searrow$ & $\searrow$ & $\nearrow$ \\
\hline
\end{tabular}

$$
\begin{aligned}
& \times \sum_{i=1}^{m}\left[h_{i}\left(x_{i}+R-L_{i}\right) \mid L_{i}-x_{i} \leq R\right] \\
& +\frac{10}{4 \times 2 \times(1-0.02)} \\
& \times(15+0.8 \times 5+(1-0.8) \times 4) \\
& \times\left[\left(L_{0}-5.975815\right)^{2}+\left(L_{0}-5.975815\right)\right] \\
& \left.\times P\left(L_{0} \geq x_{0}-R\right)\right]=\frac{100}{4}+\left[\frac{(4-1)}{2 \times(1-0.02)}\right. \\
& \times 15 \times 10+\frac{15 \times 10}{(1-0.02)} \times(5.975815-6) \\
& +\frac{10 \times 4}{(1-0.03) \times(1-0.02)} \\
& \times(5 \times 0.25+3 \times 0.375+2 \times 0.375) \\
& +\frac{10}{3 \times 4 \times(1-0.02)} \\
& \times(15+0.8 \times 5+(1-0.8) \times 4) \times 17.14291] \\
& =288.8142 .
\end{aligned}
$$

According to Table 4, if the ordering system is lot for lot, then the total cost is 463.0628 , which is achieved when periodic order quantity is equal to 1 . But for periodic order quantity system, the optimal cost is 247.8279 and it is achieved when periodic order quantity is equal to 3 .

\section{Conclusion}

This study considers the multilevel assembly systems with stochastic component lead times. A general model was utilized and the main goal of this model is to minimize the sum of inventory holding cost, backorder cost, and setup cost so as to find the optimize solution of component planned lead times and order periodicity for assembly systems.

An MRP approach with periodic order quantity (POQ) policy is utilized for the supply planning of components. A general mathematical approach is utilized for modelling multilevel MRP under uncertainty components lead times which has apparently not been studied before. Previous studies have considered one- or two-level assembly system but this study considered multilevel and multiperiod assembly system. Three theorems were utilized for finding the optimal solutions. By using this equation, optimal solution is possible.

\section{Competing Interests}

The authors declare that they have no competing interests.

\section{References}

[1] P. Burcher, "Material requirements planning," in Wiley Encyclopedia of Management, vol. 10, pp. 1-2, John Wiley \& Sons, 2015.

[2] A. Dolgui, F. Hnaien, A. Louly, and H. Marian, "Parameterization of MRP for supply planning under lead time uncertainties," in Supply Chain,Theory and Applications, V. Kordic, Ed., pp. 247-263, I-Tech Education, Vienna, Austria, 2008.

[3] D. N. P. Murthy and L. Ma, "MRP with uncertainty: a review and some extensions," International Journal of Production Economics, vol. 25, no. 1-3, pp. 51-64, 1991.

[4] J. H. Y. Yeung, W. C. K. Wong, and L. Ma, "Parameters affecting the effectiveness of MRP systems: a review," International Journal of Production Research, vol. 36, no. 2, pp. 313-331, 1998.

[5] R. Guillaume, C. Thierry, and B. Grabot, "MRP with imprecise demand and uncertain lead time," in Proceedings of the 7th Conference of the European Society for Fuzzy Logic and Technology (EUSFLAT '11), pp. 673-679, Aix-Les-Bains, France, July 2011.

[6] W. Benton, Supply Chain Focused Manufacturing Planning and Control, Cengage Learning, Boston, Mass, USA, 2013.

[7] J.-S. Song, "Effect of leadtime uncertainty in a simple stochastic inventory model," Management Science, vol. 40, no. 5, pp. $603-$ 613, 1994

[8] C. A. Yano, "Setting planned leadtimes in serial production systems with tardiness costs," Management Science, vol. 33, no. 1, pp. 95-106, 1987.

[9] C. Chu, J.-M. Proth, and X. Xie, "Supply management in assembly systems," Naval Research Logistics, vol. 40, no. 7, pp. 933-949, 1993.

[10] M.-A. Ould-Louly and A. Dolgui, “The MPS parameterization under lead time uncertainty," International Journal of Production Economics, vol. 90, no. 3, pp. 369-376, 2004.

[11] S. S. Chauhan, A. Dolgui, and J.-M. Proth, "A continuous model for supply planning of assembly systems with stochastic component procurement times," International Journal of Production Economics, vol. 120, no. 2, pp. 411-417, 2009.

[12] M.-A. Louly, A. Dolgui, and A. Al-Ahmari, "Optimal MRP offsetting for assembly systems with stochastic lead times: POQ policy and service level constraint," Journal of Intelligent Manufacturing, vol. 23, no. 6, pp. 2485-2495, 2012.

[13] H. Sadeghi, A. Makui, and M. Heydari, "Determining the periodicity and planned lead time in serial-production systems with dependent demand and uncertain lead time," Uncertain Supply Chain Management, vol. 1, no. 2, pp. 87-98, 2013.

[14] G. Li, Y.-C. Kang, and G. Xu, "Optimal decision for fashion supply chains with service level constraint and controllable lead time," Mathematical Problems in Engineering, vol. 2015, Article ID 758494, 9 pages, 2015.

[15] F. Hnaien, X. Delorme, and A. Dolgui, "Genetic algorithm for supply planning in two-level assembly systems with random lead times," Engineering Applications of Artificial Intelligence, vol. 22, no. 6, pp. 906-915, 2009.

[16] R. Sakiani, S. M. T. Fatemi Ghomi, and M. Zandieh, "Multiobjective supply planning for two-level assembly systems with stochastic lead times," Computers and Operations Research, vol. 39, no. 7, pp. 1325-1332, 2012. 
[17] F. Hnaien, X. Delorme, and A. Dolgui, "Multi-objective optimization for inventory control in two-level assembly systems under uncertainty of lead times," Computers \& Operations Research, vol. 37, no. 11, pp. 1835-1843, 2010.

[18] H. Sadeghi, A. Makui, M. Heydari, and A. H. Ghapanchi, "Proposing a model for optimising planned lead-times and periodicity in MRP systems under uncertainty," International Journal of Services and Operations Management, vol. 21, no. 3, pp. 310-331, 2015.

[19] H. Sadeghi, A. Makui, and M. Heydari, "Multi-objective optimization for inventory control in serial-production systems with dependent demand and uncertainty of lead times," MAGNT Research Report, vol. 3, no. 4, pp. 247-254, 2015.

[20] H. Sadeghi, A. Makui, and M. Heydari, "A simulation method for Material requirement planning supply dependent demand and uncertainty lead-time," African Journal of Business Management, vol. 8, no. 4, pp. 127-136, 2014.

[21] O. Ben Ammar, H. Marian, D. Wu, and A. Dolgui, "Mathematical model for supply planning of multi-level assembly systems with stochastic lead times," IFAC Proceedings, vol. 46, no. 9, pp. 389-394, 2013.

[22] O. B. Ammar, A. Dolgui, and H. Marian, "Genetic algorithm for multi-level assembly systems under stochastic lead times," in Proceedings of the 19th IFAC World Congress on International Federation of Automatic Control (IFAC '14), pp. 778-783, Cape Town, South Africa, August 2014.

[23] H.-L. Yang, "A partial backlogging inventory model for deteriorating items with fluctuating selling price and purchasing cost," Advances in Operations Research, vol. 2012, Article ID 385371, 15 pages, 2012.

[24] J. M. Proth, G. Mauroy, Y. Wardi, C. Chu, and X. L. Xie, "Supply management for cost minimization in assembly systems with random component yield times," Journal of Intelligent Manufacturing, vol. 8, no. 5, pp. 385-403, 1997.

[25] A. Dolgui and M.-A. Ould-Louly, "A model for supply planning under lead time uncertainty," International Journal of Production Economics, vol. 78, no. 2, pp. 145-152, 2002.

[26] M.-A. Louly, A. Dolgui, and F. Hnaien, "Supply planning for single-level assembly system with stochastic component delivery times and service-level constraint," International Journal of Production Economics, vol. 115, no. 1, pp. 236-247, 2008.

[27] M.-A. Louly and A. Dolgui, "Optimal time phasing and periodicity for MRP with POQ policy," International Journal of Production Economics, vol. 131, no. 1, pp. 76-86, 2011.

[28] O. Tang and R. W. Grubbström, "The detailed coordination problem in a two-level assembly system with stochastic lead times," International Journal of Production Economics, vol. 8182, pp. 415-429, 2003.

[29] S. Axsäter, "Planning order releases for an assembly system with random operation times," in Stochastic Modeling of Manufacturing Systems, pp. 333-344, Springer, Berlin, Germany, 2006. 


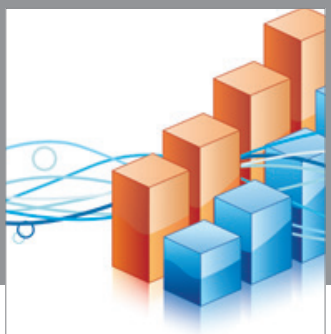

Advances in

Operations Research

vatem alat4

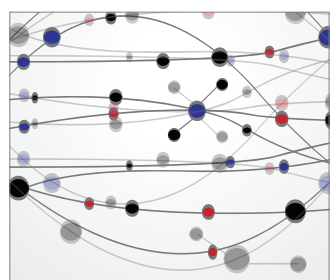

\section{The Scientific} World Journal
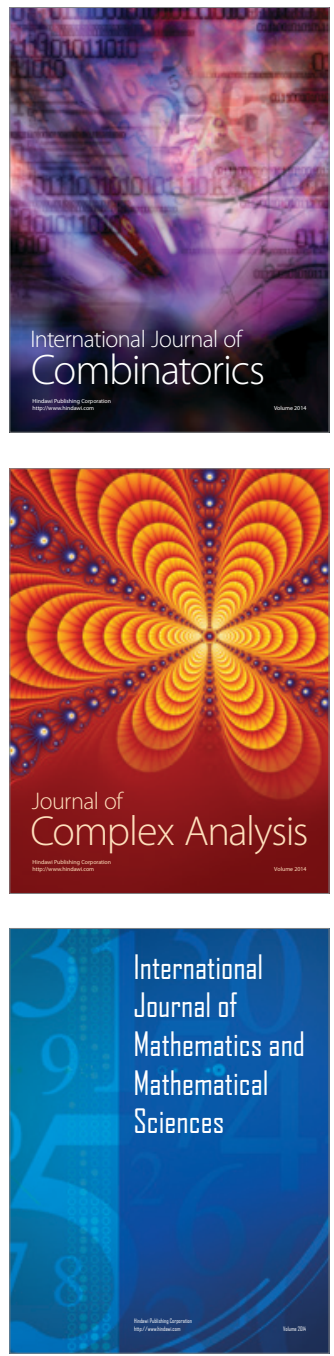
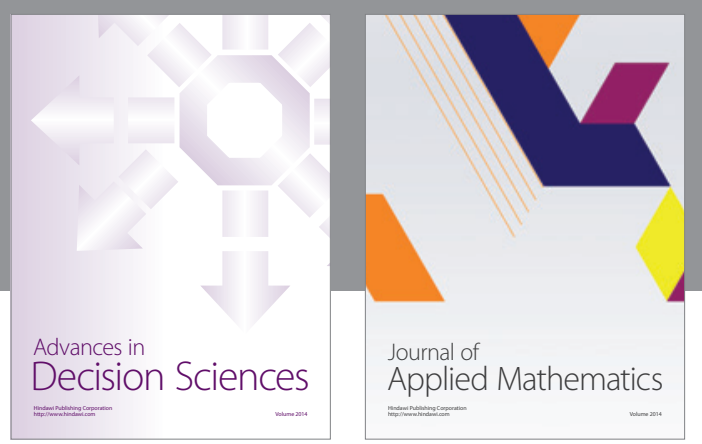

Algebra

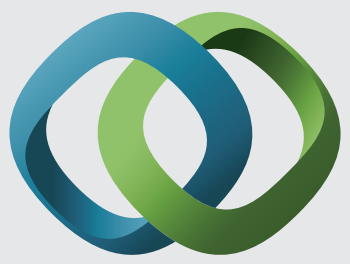

\section{Hindawi}

Submit your manuscripts at

http://www.hindawi.com
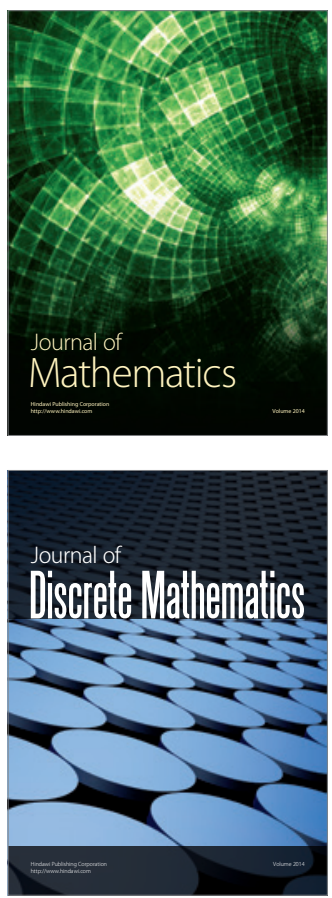

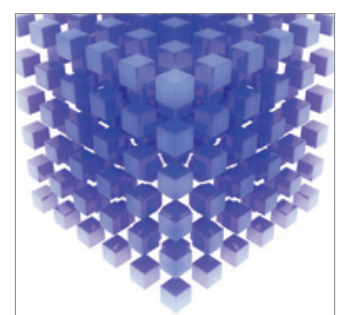

Mathematical Problems in Engineering
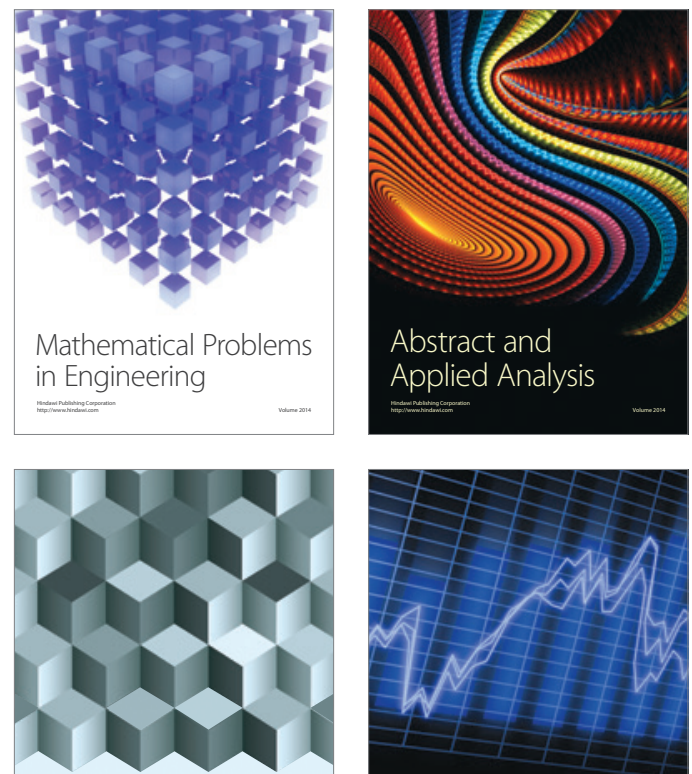

Journal of

Function Spaces

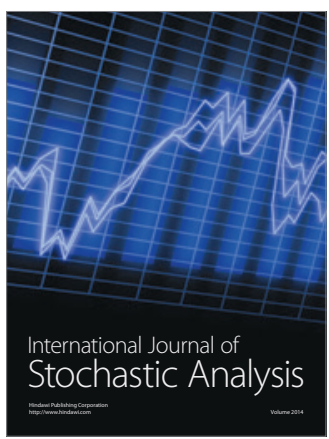

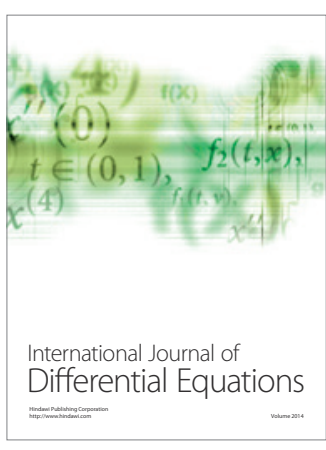
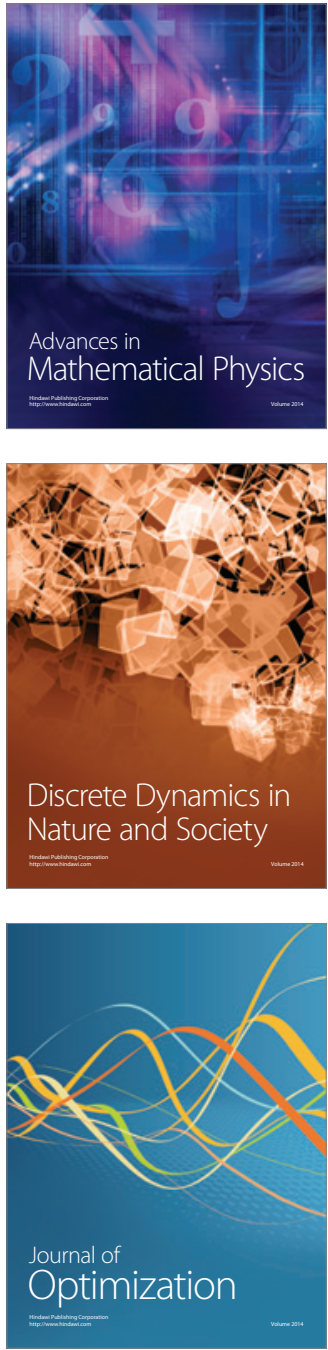